\title{
Do desejo de traduzir à transcriação: apontamentos sobre a decodificação jornalística do discurso científico, com base em conceitos de Haroldo de Campos, José Paulo Paes e Paul Ricoeur
}

\section{Maurício Guilherme Silva Jr. e Elton Antunes}

\section{Resumo}

Os mecanismos jornalísticos de decodificação e edição do discurso da ciência implicam a necessidade de ressignificação das investigações especializadas, ligadas às mais diversas áreas do conhecimento, e a sublimação da terminologia técnica - transfigurando-a em narrativa dialógica, com linguagem e formato mais próximos à(s) experiência(s) daquele a quem se destina (leitor, espectador, usuário, etc.). Baseado na noção de transleitura, proposta por José Paulo Paes (1995), em diálogo com os desafios do processo de tradução abordados por Paul Ricoeur (2011), este artigo reflete sobre 0 uso do neologismo "transcriação" - criado por Haroldo de Campos - para discussão de práticas ligadas à cobertura da ciência pelo jornalismo.

\section{Palavras-Chave}

Jornalismo científico; Transleitura; Transcriação; Haroldo de Campos, José Paulo Paes, Paul Ricoeur.

Maurício Guilherme Silva Jr. I mgsj@uol.com.br Doutor em Estudos Literários pela Universidade Federal de Minas Gerais, Brasil. É professor do curso de Jornalismo do Centro Universitário de Belo Horizonte (UniBH). Integra o Programa de Comunicação Científica e Tecnológica da Fundação de Amparo à Pesquisa no Estado de Minas Gerais, onde é pesquisador e editor da revista Minas Faz Ciência.

Elton Antunes I eltunes@uol.com.br

Doutor em Comunicação e Cultura Contemporânea pela Universidade Federal da Bahia, Brasil. Professor da Universidade Federal de Minas Gerais, pesquisador permanente do PPGCOM/UFMG e integrante do Grupo de Pesquisa Imagem e Sociabilidade (Gris). Coordenador do Programa de Pós-Graduação em Comunicação da UFMG.

\section{Introdução}

No dia 14 de fevereiro de 1990, certa decisão estratégica da Nasa, a agência espacial norteamericana, resultaria em visões especialmente marcantes para a trajetória da humanidade. $\mathrm{Na}$ referida data, a sonda Voyager I encontrava-se a cerca de 6 bilhões de quilômetros da Terra e, já quase sem combustível, partiria em direção ao infinito cósmico. Estimulados pelo escritor e astrônomo Carl Sagan, os controladores da astronave consideraram viável transmitir sinais de comando, espaço afora, para a derradeira manobra de sua máquina de exploração. Nos meses subsequentes, a pequenina câmera da Voyager lhes reenviaria impressionantes registros visuais do sistema solar. Dentre as imagens em movimento, a mais espetacular dizia respeito à Terra, morada daqueles e de tantos outros pesquisadores: em meio a inúmeras estrelas, o planeta revelavase como mera "manchinha azul com diâmetro inferior a um pixel, iluminada por um raio de Sol refletido na superfície da nave" (LYNCH; MOSLEY, 2011, p. 7). 
Tal rara cena é reveladora não apenas da procura do homem por respostas aos mistérios da natureza, mas, principalmente, da eminência do registro e da (posterior) disseminação narrativa do(s) diverso(s) e ininterrupto(s) acontecimento(s) e experiência(s) da vida em movimento. Há que se considerar, neste sentido, a máxima de que certos objetos, seres e fatos "ocultos" só poderão atingir "novo status, como algo público"1 (THOMPSON, 2008, p. 16), graças ao registro dos meios tecnológicos - e/ ou jornalísticos -, a evidenciar o que antes era invisível aos olhos. De outro modo, pode-se afirmar que certas ocorrências ganham "existência social"2 apenas quando devidamente expostas, descritas, narradas, publicizadas.

Ao referido processo de exposição e publicização dos acontecimentos, por meio dos sistemas de comunicação e informação do mundo moderno com ênfase nas "mídias massivas" -, Thompson (1998; 2008) dará o nome de "visibilidade mediada". Na concepção do autor, a partir do desenvolvimento da imprensa e de outros diversos aparatos comunicacionais, "novas formas de agir e interagir são criadas, considerando-se suas propriedades distintivas específicas" (THOMPSON, 2008, p. 17). Neste artigo, interessanos problematizar o(s) modo(s) como o jornalismo - ou, mais precisamente, o processo de edição jornalístico - enuncia ${ }^{3}$ e "traduz" as temáticas científicas, de forma que ganhem visibilidade e, em seguida, transformem-se em "material" apto ao debate e à valorização social.

Ao longo dos séculos, a relação entre divulgação e recepção pública da ciência mostra-se fundamental à compreensão das peripécias do homem à cata do conhecimento. Assim como vídeos produzidos por sofisticados aparatos técnicos - a exemplo das câmeras da Voyager I - podem, atualmente, revelar seres e realidades antes distantes do cotidiano dos indivíduos, inúmeras iniciativas, desenvolvidas desde,

Em A nova visibilidade, Thompson (2008) não analisa a divulgação midiática de imagens científicas, mas a difusão, em 2004, de cenas alusivas à tortura de prisioneiros iraquianos, ação empreendida por soldados norte-americanos em Abu Ghraib, prisão controlada pelos EUA na periferia de Bagdá.

2 Tal referência não diz respeito ao "processo de midiatização da sociedade", temática investigada por muitos teóricos da comunicação. Neste trabalho, pretende-se ressaltar, tão somente, a relevância dos aparatos tecnológicos para a exploração e a exposição do "mundo da vida".

30 infinitivo, neste caso, arvora a delimitação do princípio de "enunciação jornalística" como prática mediadora - no caso, entre público e ciência. Destaque para o comentário de Vizeu (2003), que, a partir das teorias da enunciação, busca compreender a produção de sentidos no jornalismo. "Um texto jornalístico é, por isso, um ato de linguagem que consiste no desdobramento de um trabalho de transformação, feliz ou infeliz, provocado pelas ações que a enunciação põe em cena, colocando, assim, em relação duas temporalidades-limite, um antes e um depois, mediante uma temporalidade transformadora de mediação" (VIZEU, 2003, p. 113).

0 verbo aparece entre aspas devido à fragilidade das prerrogativas inatas ao conceito de tradução, no que diz respeito à tentativa de, por meio da narrativa jornalística, tornar menos complexos, ao público leigo, os discursos da ciência. A temática será melhor explicitada neste artigo. 
principalmente, 0 século XVI, pretendem 0

desnudamento - e a posterior "tradução" - de

uma série de enigmas da vida, assim como a

subsequente propagação de tais descobertas.

Em artigo sobre a construção de uma espécie de "barômetro da ciência e da tecnologia na mídia", Vogt et al (2006) recorrem à trajetória do filósofo, ceramista e "conferencista" Bernard de Palissy (cerca de 1510-1590) - que, em seu ateliê, promovia debates sobre artes, teorias e métodos para destacar a intrínseca relação entre processos comunicativos e valorização social da ciência:

A história de Palissy (e, mais tarde, a de Galileu) não representa um caso à parte. É apenas um exemplo, dentre tantos, da relação indissociável entre ciência e comunicação (Eisenstein, 1998). Seja por meio de epistolários ou conferências públicas, de livros ou revistas, de museus, coleções, tábuas anatômicas, seja, hoje em dia, por meio de softwares, listas de discussão e open archives, congressos, workshops, networks de pesquisa: a ciência, em cada uma de suas fases, sempre foi fortemente ligada a formas variadas de difusão, arquivamento, discussão da informação e do conhecimento. É fácil concordar com o historiador da ciência Paolo Rossi, que diz que a ciência nasce quando a comunicação do conhecimento - que era considerada intrinsecamente negativa no âmbito dos saberes herméticos e alquímicos - se transforma num valor [...]" (VOGT et al, 2006, p. 2).

Prática hoje aclimatada em múltiplas searas de produção da informação (jornais, revistas, rádios,
TVs, internet, etc.), o jornalismo científico apresenta-se, na atualidade, como ofício vital à difusão, à tradução e à valorização dos discursos e descobertas da ciência. Por meio da experimentação de formatos aptos a remodelar a linguagem e o conteúdo especializados, diversas iniciativas jornalísticas lançam-se ao desafio de transformar em valor as dúvidas - e não apenas as "certezas" - estimuladoras da ciência e da tecnologia.

Ao usar aqui o termo valor - à maneira do que fazem Vogt et al (2006) -, não se pretende defender que apenas os "bons efeitos" da ciência sejam disseminados ao público consumidor de informação. Afirma-se, ao contrário, a necessidade do que Santos (1989) tratará por "desdogmatização" das práticas científicas. Tratase do estímulo ao permanente olhar crítico com relação aos modos de produção do conhecimento. Ciência, pois, caracteriza-se como o "território" propício às inquirições, e não às certezas absolutas.

Afinal, de que modo abordar jornalisticamente a inquirição do saber, atividade humana calcada em métodos, "crises" e dúvidas, senão por meio do questionamento de tudo o que diga respeito ao desenvolvimento das próprias pesquisas - das fontes de financiamento ao histórico epistemológico do(s) tema(s) abordado(s), 
das motivações subjetivas do(s) estudioso(s) à natureza ética das investigações, dos fins sociais da(s) iniciativa(s) ao estatuto estético-científico da(s) abordagem(ns) proposta(s)?

Neste artigo, propõe-se, justamente, a teorização de princípios editoriais desenvolvidos por jornalistas especializados na cobertura da ciência, com ênfase na criação de narrativas interessadas em decodificar, com foco no "público leigo", a natureza e 0 valor dos métodos e das incertezas inerentes à ânsia pela busca do conhecimento. Para tal, recorreu-se, como ponto de partida, ao conceito de "transcriação", cunhado e teorizado por Haroldo de Campos, em diversos artigos com vistas, porém, à discussão dos complexos mecanismos de tradução de textos literários.

Em outros termos, pretende-se, aqui, aproximar a proposta de recriação crítica de Campos elaborada, conforme ressaltado, para renovar as possibilidades de tradução literária - ao "território" das práticas do jornalismo científico, que, a seu modo, também se alimenta da recriação de discursos, com o intuito de ampliar a capacidade de compreensão, pelo público leigo, de certas nuances da produção do conhecimento.

Pretende-se, ainda, recorrer ao conceito de "transleitura”, criado pelo crítico José Paulo
Paes (1995) - também em função de questões do campo literário -, e a escritos do filósofo Paul Ricoeur (2011) sobre o ofício da "tradução". Almeja-se, dessa maneira, a reencenação do conceito haroldiano de "transcriação" no âmbito das práticas do jornalismo científico, como termo representativo dos necessários mecanismos recriadores do discurso científico.

Parte-se, por fim, do entendimento de "edição jornalística" não apenas como prática responsável por definir espaços e dimensões das narrativas em diversos formatos - bem como pela determinação de "lugares" próprios a cada assunto, pelo acompanhamento da elaboração imagética e pela premiação de trabalhos e condutas (PEREIRA JR., 2001) -, mas, também, como forma de mediação apta a explorar possibilidades de estímulo ao diálogo entre a ciência ("universo" composto por especialistas, instituições, etc.) e a sociedade. Trata-se, em suma, de projetos de edição responsáveis por narrativas que problematizem princípios cartesianos e positivistas ainda hoje correntes no próprio discurso científico.

\section{Disseminação do saber}

Em artigo acerca dos efeitos da ciência sobre as atitudes da humanidade ${ }^{6}$, Reis (1968) afirma que, finda a Idade Média, a ânsia humana por 
investigar - e narrar - 0 mundo seria responsável pelo desenvolvimento das práticas e princípios científicos. Em outras palavras, o desnudamento e a exposição de tudo o que, até então, parecia "oculto" configuram-se como fundamentais ao desabrochar da chamada "revolução científica" e dos movimentos humanistas, que, a partir do século XV, passam a tratar "o homem como centro de todas as coisas".

Como exemplos dessa profícua aproximação entre espírito científico e estratégias para divulgação das descobertas e dos resultados, ressaltam-se as figuras de Leonardo da Vinci (1452-1518) e Andreas Vesalius (1514-1564), senhores das artes e das ciências, os quais, já no período seiscentista, dissecam o corpo humano - antes sacralizado como forma de melhor compreender as estruturas anatômica e fisiológica dos indivíduos (REIS, 1968). Como fruto dessa criteriosa dissecação de cadáveres, nascem os primeiros tratados de anatomia e fisiologia de que se tem notícia, obras nas quais as imagens - e as narrativas analíticas - seriam responsáveis por redefinir, à época, a relação entre o homem e seu próprio corpo.

Apesar da distância de mais de quatro séculos a separar as experiências de Da Vinci e Vesalius das imagens coletadas e retransmitidas ao homem por meio da sonda Voyager I, é possível afirmar que, em todos os casos, a divulgação dos resultados estimulou a sociedade a substituir, ou mesmo a negar "pequenas verdades" absolutas, muitas das quais cristalizadas pelas tradições (REIS, 1968).
Neste sentido, há que se ressaltar Bronowski (1986), para quem a maneira científica de pensar transformou-se em uma espécie de "disciplina unificadora", ao representar a tentativa do homem em ver e compreender o mundo como um todo.

Pelo que se percebe, a necessidade de exposição e discussão de metodologias, teorias e princípios sempre esteve atrelada à investigação do conhecimento. Desde fins do século XVI, a divulgação dos processos e resultados das investigações científicas afirma-se não só como garantia da superação de obstáculos técnicos e/ ou éticos (MOSLEY; LYNCH, 2011; REIS, 1968) - fruto do diálogo entre "pares" -, mas, também, como possibilidade de obtenção do crivo social em relação aos propósitos da ciência, atividade humana expressa por Bronowski (1986, p.12) como "uma interpretação especial", por ser 0 mais sofisticado dos métodos de planejamento já inventados sobre a Terra para compreensão do mundo. Segundo o autor, em primeiro lugar,

a ciência não é uma actividade dissociada, independente e vazia de valores que pode ser levada a efeito separadamente do resto da vida humana, porque, em segundo lugar, ela é, pelo contrário, a expressão, numa forma muito precisa, do comportamento humano específico da espécie, que se centra na produção de planos. Em terceiro lugar, não há distinção entre estratégias científicas e estratégias humanas para orientar o nosso ataque a [sic] longo prazo sobre como viver e como olhar para o Mundo. A ciência é uma visão do Mundo baseada na noção de que podemos planear através do entendimento (BRONOWSKI, 1986, p. 26-27). 
Frente ao pressuposto de que os seres humanos orientam sua conduta segundo os planos que realizam - com peculiar intensidade e senso de organização no campo da ciência -, fica clara a necessidade de divulgação, a diversos públicos, das práticas e teorias científicas. Trata-se, afinal, da produção de saber capaz de alterar, significativamente, o cotidiano dos indivíduos. Além disso, a ciência deve chegar a todos em função de a procura pelo conhecimento revelar-se como "condição do destino humano, que nos faz seres curiosos e tenazes" (SILVA, 2010, p. 25).

Se, na atualidade, o conhecimento científico goza de grande "legitimidade social, tendo atingido, em muitas circunstâncias, o lugar da verdade que a religião ocupou até a Revolução Francesa no mundo ocidental" (SILVA, 2010, p. 25), houve momentos de ampliação do abismo entre as demandas sociais e os propósitos da ciência. Que o diga a explosão de ogivas nucleares nas cidades japonesas de Hiroshima e Nagasaki, episódio de encerramento da

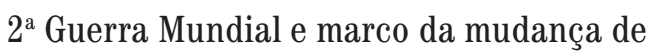
atitude dos indivíduos, no século XX, para com os objetivos da pesquisa aplicada no mundo: antes interessada apenas nas benesses ${ }^{7}$ produzidas pelos cientistas, a comunidade internacional atenta-se, então, para os perigos do desenvolvimento tecnológico e científico - no caso, exemplificados pelos efeitos proporcionados com 0 aprimoramento das técnicas de manipulação do urânio.

Ao longo dos séculos, portanto, revela-se multifacetado o posicionamento crítico das sociedades em relação aos interesses, métodos e propósitos da ciência. Daí a necessidade, como ressalta uma série de autores - Burkett (1990); Colombo (1998); Bueno (2001); Orlandi (2001); Zamboni (2001); Nunes (2001); Guimarães (2001); Oliveira (2002); Silva (2010); Fagundes (2010); Maia (2010); Leite (2010) e Costa (2010) -, do estabelecimento de práticas efetivas de divulgação científica, ao traduzir, para o público leigo, as complexidades inerentes à produção do conhecimento nas mais diversas áreas, assim como de inquirir os pesquisadores e as instituições quanto a seus objetivos, métodos e teorias.

\section{0 tratamento jornalístico da ciência}

Se a divulgação científica no Ocidente se inicia há milênios - pois que a atividade remonta aos gregos, encarregados de "registrar e difundir 0 que seus sábios formulavam" (SILVA, 2010, P.26) -, no que se refere à difusão da ciência por meio dos processos e das lógicas do fazer jornalístico, a profissionalização dá-se com a evolução técnica dos meios de difusão da informação e o desenvolvimento das chamadas "sociedades industriais", já a partir do século XVII. Neste 
sentido, segundo a autora, o jornalismo científico assume, progressivamente, a responsabilidade de garantir espaço para a ciência "na esfera pública midiática, primando pela difusão das informações e respeitando a pluralidade das perspectivas e a diversidade das fontes relacionadas aos temas abordados" (SILVA, 2010, p. 27).

Para Colombo (1998), tais fontes científicas têm características bastante peculiares: em função de seu alto grau de especialização, desencoraja nos jornalistas, por vezes, a verificação de dados e informações. No caso do jornalismo científico, é permanente a inquirição quanto à veracidade de tudo o que é relatado pelos pesquisadores. 0 autor chama a atenção, ainda, para a necessidade de ampla contextualização das reportagens no campo da ciência, uma vez que todas as etapas da produção científica devem ser compreendidas, e, caso necessário, minuciosamente relatadas.

Já conforme Peters (2000), o tratamento jornalístico à ciência mudou ao longo do século XX: a "cobertura popularizante" dos sucessos da prática científica foi, aos poucos, fazendo-se acompanhar da descrição dos impactos menos benéficos, a exemplo de desastres ambientais, problemas relacionados à saúde, à ética e à segurança. Além disso, dá-se 0 que 0 autor chama de "politização da ciência", processo pelo qual os resultados das pesquisas especializadas passam a legitimar, ou não, decisões políticas.
Ao também discutir importantes questões dos princípios da política, Bueno (2001) enfatiza a necessidade de se "resgatar o caráter pedagógicocrítico do jornalismo científico, evitando que os profissionais estejam a serviço de interesses que atentem contra a cidadania e a função social da ciência”. Nesta seara de discussão, Oliveira (2002) afirma que, para consolidação das bases da cidadania de uma nação, é preciso de investimento em cultura científica.

Desse modo, o jornalismo científico seria 0 meio apto a disseminar, democraticamente, as informações detalhadas acerca da produção do conhecimento. Ter acesso aos avanços e às aplicações práticas da ciência é direito expresso dos cidadãos, bem como a divulgação se revela "obrigação dos órgãos que a produzem ou patrocinam" (MAIA, 2010, p. 23). Por fim, no artigo Breve ensaio sobre as peculiaridades do texto de divulgação científica ${ }^{8}$, Destácio (2000) sumariza uma série de "mandamentos", desenvolvida por três importantes pesquisadores ${ }^{9}$ das especificidades do jornalismo científico: a) oferecer, à maioria, o patrimônio da minoria; b) difundir os descobrimentos, de modo a ressaltar seu valor para a humanidade; c) destacar a importância da ciência pura; e) combater a desconfiança social em relação à ciência; f) revelar o caráter coletivo da prática científica; g) denunciar as falsas ciências; h) utilizar-se 
de meio interessante, direto e sensato para a difusão de informações acerca da ciência; i) ser simples, direto e "nobre"; j) tratar um assunto de cada vez; k) pensar muito no tema antes de escrever; l) humanizar os relatos; m) evitar jargões jornalísticos, n) adequar forma e linguagem ao público e o) distinguir especulações de resultados. Percebe-se, assim, em tais compreensões acerca do papel do jornalismo que cobre o fazer científico uma evidente expectativa em "traduzir" o fazer e a linguagem especializada da ciência, de maneira a oferecer outras formas de inteligibilidade de tais práticas a uma coletividade mais ampla.

Com foco nas especificidades teóricas e práticas do jornalismo científico anteriormente indicadas, chega-se a questões centrais ao processo de edição jornalística por trás de narrativas responsáveis por promover diálogos frutíferos entre ciência e sociedade. Em primeiro lugar, parte-se do ideal de edição jornalística como atividade ligada à decodificação dos discursos especializados, elaborados em diversas áreas do saber, de forma a problematizar os significados - éticos e sociopolíticos, principalmente - da produção de conhecimento e de inovação tecnológica.

Neste artigo, optou-se por manter, como horizonte de problematização, práticas jornalísticas calcadas no estímulo à cobertura experimental de temáticas referentes à ciência, de modo a desenvolver narrativas amparadas em princípios como contextualização informacional e instauração de diálogos críticos com o(s) público(s)-alvo. Trata- se, grosso modo, de experiências interessadas em "dizer a ciência” a partir da dúvida, e não consubstanciada por princípios e horizontes cartesianos - ainda hoje presentes no discurso da própria ciência.

Bastante importantes ao ciclo de afirmação da ciência moderna, a partir do século XVI - quando certos homens lutavam por compreender as coisas e os seres para além das crenças, das culpas e dos poderes religiosos -, filósofos como René Descartes (1596-1650) revelaramse fundamentais à ordenação do pensamento metodológico. Com o passar dos tempos, porém, os princípios ordenadores de tais pensadores, que nutriam "a missão de unificar todos os conhecimentos humanos a partir de bases seguras que conformariam uma 'ciência admirável', iluminada pela verdade e pelas certezas racionais" (MOZZINI, 2012, p. 107), tornaramse problemáticos, principalmente por reduzir a pesquisa científica a demonstrações amparadas na ideia de exatidão.

Hoje, quando se fala em decodificar/traduzir jornalisticamente 0 universo da ciência, é vital que se imagine o investimento em coberturas contextualizadoras, amparadas na construção de narrativas complexas - as quais, aliás, poderão se alimentar de construções visuais metafóricas e de recursos linguísticos próximos ao discurso literário -, com 0 intuito de perseguir algumas das metas delineadas por Destácio (2000) como essenciais à prática do jornalismo científico, e, desse modo, 
estimular 0 debate de concepções em torno do(s) valor(es) da ciência para a humanidade.

\section{4 "Transcriação" em Haroldo de Campos e o problema do traduzir}

Em dezenas de artigos e ensaios, o crítico, professor e escritor Haroldo de Campos (19292003) problematizou os complexos mecanismos da tradução poética. 0 autor chegou, mesmo, a edificar as bases de importante (e particular) teoria da "tradução" muitos foram os modos de enfoque destinados à temática - de abordagens gerais, como em "Da tradução como criação e como crítica", "Tradução: fantasia e fingimento" e "Texto literário e tradução", a nuances específicas, a exemplo de "Tradução, ideologia e história" e "Para além do princípio da saudade: a teoria benjaminiana da tradução".

Quanto ao termo "transcriação" - engendrado como forma de discutir o princípio de "tradução criadora" (SANTAELLA, 2005) -, Campos escreveu uma série de trabalhos ligados à semiologia. Dentre outros, ressaltem-se, aqui, "Da transcriação: poética e semiótica da operação tradutora", "Tradução e reconfiguração: 0 tradutor como transfingidor", "Tradução/Transcriação/ Transculturação" e "Tradição, transcriação e transculturação: 0 ponto de vista do ex-cêntrico".
Em sua obra, muito além de explicações técnicas para o mecanismo da tradução interssemiótica, Campos salientou a urgência de se compreender a prática tradutória (na poesia, principalmente) como "empresa de natureza estética, análoga à própria criação" (TÁPIA, 2015, p. 12). 0 autor pretendia, pois, negar a ideia de mecanismos tradutórios simplificados - com destaque ora para questões rítmicas, ora para temáticas de conteúdo literal -, por meio de processos de recriação estética baseados no "isomorfismo", conceito a destacar a união possível entre as línguas de "chegada" e de "partida".

Na visão de Campos, obtém-se, pela tradução "em outra língua, uma outra informação estética, autônoma, mas ambas [...] ligadas entre si por uma relação de isomorfia: serão diferentes enquanto linguagem, mas, como os corpos isomorfos, cristalizar-se-ão dentro de um mesmo sistema" (CAMPOS apud TÁPIA, 2015, p. 12). No entanto, não há técnica única para orientar os tradutores de maneira generalizada: ao ser traduzida, cada nova narrativa implicará, necessariamente, "transcriações" elaboradas em paisagens específicas.

Conforme enfatiza Santaella (2005, p. 222), importante ressaltar, ainda, que Campos valorizava a dialética entre elementos macro e microestéticos. No caso da tradução de textos 
literários, 0 investimento em soluções dialéticas poderia superar a mera "réplica aproximativa". Daí o principal paradoxo a ser discutido por Campos 0 qual, neste artigo, revela-se vital à compreensão da reapropriação "transcriadora", pelo jornalismo, de discursos da ciência: a própria impossibilidade de tradução literal é responsável pela recorrência à recriação.

Neste sentido, Campos admite a necessidade de "diversas opções e objetivos tradutórios, desde que vinculados à concepção fundamental da natureza estética do texto poético" (TÁPIA, 2015, p. 19). Além disso, ao citar Paulo Rónai (1956), o autor sublinha que a "demonstração da impossibilidade teórica da tradução literária implica a assertiva de que tradução é arte" (CAMPOS, 2015, p. 5).

Então, para nós, tradução de textos criativos será sempre recriação, ou criação paralela, autônoma porém recíproca. Quanto mais inçado de dificuldades esse texto, mais recriável, mais sedutor enquanto possibilidade aberta de recriação. Numa tradução dessa natureza, não se traduz apenas o significado, traduz-se o próprio signo, ou seja, sua fisicalidade, sua materialidade mesma [...] (CAMPOS, 2015, p. 5).

No que se refere, diretamente, ao resultado de tal mecanismo de recriação - a "transcriação" -, Campos (2015, p. 78) comenta a necessária "reelaboração neológica" para que se pudesse fazer jus à complexidade dos mecanismos tradutórios:

Desde a ideia inicial de recriação, até a cunhagem de termos como transcriação, reimaginação (caso da poesia chinesa) transtextualização, ou - já com timbre metaforicamente provocativo
- transparadisação (transluminação) e transluciferação, para dar conta, respectivamente, das operações praticadas com Seis Cantos do Paraíso de Dante (Fontana, 1976) e com as duas cenas finais do "Segundo Fausto" (Deus e o Diabo no Fausto de Goethe, Perspectiva, 1981). Essa cadeia de neologismos exprimia, desde logo, uma insatisfação com a ideia "naturalizada" de tradução, ligada aos pressupostos ideológicos de restituição da verdade (fidelidade) e literalidade (subserviência da tradução a um presumido "significado transcendental" do original) - ideia que subjaz a definições usuais, mais "neutras" (tradução "literal"), ou mais pejorativas (tradução "servil"), da operação tradutora.

\section{5 "Tradução" e "transleitura": diálogos com 0 jornalismo}

Após breve relato dos elementos básicos a configurar o processo de "transcriação", conceito de Haroldo de Campos, almeja-se, aqui, aproximar tal problematização das definições de "tradução" e "transleituras", respectivamente, conforme Paul Ricoeur (1913-2005) e José Paulo Paes (19261998), de maneira a oferecer elementos teóricos para refletirmos acerca de aspectos fulcrais na compreensão do jornalismo científico.

Ao abordar as acepções de tradução segundo 0 filósofo francês, pretende-se alicerçar o debate em duas questões centrais: a primeira diz respeito a típico posicionamento do pensador, que enxergava a narrativa não apenas como instância polissêmica de espaço/tempo, já que a palavra constrói e dissemina significações, mas como "território" de explicitação do agir e do sofrer humanos - duo de dimensões que, na visão de 
Villela Petit (2007, p. 8), ocupa "prioritariamente a atenção" do autor.

Em segundo lugar, a relevância do ethos na obra de Ricoeur revela-se imprescindível às pretensões da discussão aqui empreendida: de modo bastante específico, pode-se dizer que, ao recorrermos à analogia entre tradução/recriação/ transcriação, como forma de pensar a relação entre o(s) discurso(s) da ciência e as operações do jornalismo científico, indicamos que tal prática configura, em si, um ato ético. Afinal, desde que a revolução científica redefiniu o lugar do pensamento metodológico, as inovações e descobertas relativas à produção do conhecimento precisam ser divulgadas, percebidas e assentidas em sua dimensão social - especialmente no que tange aos efeitos sobre o cotidiano dos indivíduos.

No olhar de Ricoeur (2011) "sobre a tradução"11, importante destacar que se trata de abordagem categoricamente relacionada ao ato de traduzir textos de um idioma a outro. Em outras palavras: nos três textos do autor francês abordados neste tópico, não há referência ao jornalismo nem ao discurso da ciência. Tal advertência serve ao propósito de explicitar que os comentários do filósofo são, neste artigo, "transportados" a outro universo temático.

Um dos pontos centrais da análise de Ricoeur refere-se à ideia de que 0 ofício da tradução - à maneira do que ressalta Haroldo de Campos (2015) - "implica a aceitação de uma perda" (LAVELLE, 2001, p. 8). Neste caso, ao falar de consentimento, 0 autor mostra desprezo pela tradição teórica acostumada a realçar as "impossibilidades" como algo inerentemente negativo ao ato de traduzir. Trata-se, em outros termos, da ideia de que certas expressões - dos chistes aos versos, das metáforas às onomatopeias - são intraduzíveis, tanto do ponto de vista linguístico quanto sob a ótica da reconfiguração cultural.

Curiosamente, na visão do pensador francês, para que 0 trabalho de tradução se revele realmente significativo, é preciso, em primeiro lugar, assumir a importância - criativa, diríamos nós; recreativa ou transcriadora, diria Campos (2015) do "luto" gerado por tais impossibilidades linguísticas, semióticas ou culturais. Afinal, esse luto permite também assumir as duas tarefas
reputadas discordantes de "levar o autor ao lei-
tor" e de "levar o leitor ao autor". Em resumo,
a coragem de assumir a problemática bem co-
nhecida da fidelidade e da traição: voto/suspei-
ta. Mas de qual tradução perfeita fala essa re-
núncia, esse trabalho do luto? Lacoue-Labarthe
e Jean-luc Nancy conceberam uma versão da
tradução perfeita válida para os românticos ale-
mães sob o título de Absoluto literário (RICOEUR,
2011, p. 28). Ao abordar o "absoluto" de que falam os escritores e intelectuais do Romantismo na Alemanha, 0 
autor trabalha - e desmi(s)tifica - algo realmente imprescindível: o sonho, partilhado por muitos, de que seria possível uma espécie de "tradução perfeita", elaborada a partir de uma "racionalidade totalmente desprovida de imposições culturais e de limitações comunitárias" (RICOEUR, 2011, p. 28-29). Para Ricoeur, porém, 0 ato de traduzir implica (ou "deseja"), justamente, uma série de perdas e impossibilidades - vicissitudes resultantes, na verdade, do exercício de transposição de um universo narrativo a outro. Para 0 autor, o luto da tradução absoluta é, paradoxalmente, 0 grande responsável pela "felicidade de traduzir" (RICOEUR, 2011, p. 29).

Desse modo, aliás, nasce 0 conceito de "hospitalidade linguística", criado por Ricoeur com o propósito de tratar da gratificação recebida pelo tradutor em função do "horizonte razoável do desejo de traduzir". A definição é um modo de enfatizar que 0 "prazer de habitar a língua do outro é compensado pelo prazer de receber em casa, na acolhida de sua própria morada, a palavra do estrangeiro" (RICOEUR, 2011, p. 30). A inter-relação entre o "outro" (0 estrangeiro) e a "casa" (a língua materna) ${ }^{12}$ pode ser também compreendida, em Ricoeur, a partir de "duas vias de acesso"13, inerentes ao ato de traduzir: a primeira refere-se à possibilidade de transferência de mensagens de uma língua a outra; a segunda, à interpretação do conjunto de significantes no interior de uma mesma comunidade linguística.

A partir dessa dupla concepção do ofício da tradução, 0 autor chega ao cerne de sua proposta: que tal substituir o velho dilema do "traduzível versus intraduzível" pelo ideal expresso na máxima "fidelidade versus traição"? Que tal, em outros termos, pensar na possibilidade de uma "equivalência presumida, não fundada numa identidade de sentido demonstrável", que se ampare no compromisso ético com os "dois mestres" a que se sujeita 0 tradutor - quais sejam, "0 estrangeiro em sua estrangeiridade" e 0 leitor e "seu desejo de apropriação" (RICOEUR, 2011, p. 47).

No que tange às narrativas jornalísticas no campo da ciência, a procura pela chamada "equivalência presumida" exige, dos editores e/ ou responsáveis pela formatação de discursos informativos - em dispositivos vários, da internet aos meios impressos e audiovisuais -, uma série de procedimentos específicos, para que, ao mesmo tempo, seja possível conservar o rigor e a natureza própria às "estrangeiridades" (no caso, métodos e teorias científicas) e estimular o leitor/ ouvinte/usuário a compreender e a se apropriar do discurso "traduzido".

É neste ponto, para que se amplie 0 debate acerca dos mecanismos de "tradução" jornalística da 
ciência - com ênfase nos processos de edição -, se optou pela aproximação entre as ideias de Campos (2015), Ricoeur (2011) e nuances do pensamento do escritor e crítico paulista José Paulo Paes (19261998), criador do neologismo transleitura -, termo, aliás, que resume, com propriedade, a relação do referido poeta - como também do ensaísta, do tradutor e do cidadão participante - com a cultura e a arte de seu tempo.

Nas palavras do autor: "0 prefixo trans- visa simplesmente, no caso, a acentuar que a leitura de uma obra literária é um ato de imersão e de distanciamento a um só tempo. Tal duplicidade do ato de leitura responde, simetricamente, à duplicidade do ato de criação literária" (PAES, 1995, p. 5). 0 termo "transleitura", pois, incorpora a ideia de que cada nova obra surgida no mundo integra um complexo sistema, "formado teoricamente por todas as obras literárias jamais escritas e por todas as interpretações ou comentários críticos que vêm suscitando" (PAES, 1995, p. 5). Neste panorama, segundo o poeta, a literatura deveria ser considerada uma espécie de corredor de ecos, em que uma voz responde à outra e vai-se formando aquele coro de vozes isoladas de certo modo se articulando. É aquela idéia baudelariana das correspondências, só que transposta do plano da criação poética para o plano da análise crítica. Quando você lê um livro, ele traz à sua lembrança os outros livros que você leu. É uma espécie de tentativa de close reading com far reading, de misturar o microscópio com o telescópio (PAES, 1995, p. D4).
0 transleitor José Paulo Paes, assim como 0 poeta, acreditava na ideia de que uma leitura só se tornaria completa caso o receptor demonstrasse sensibilidade às "instigações extratextuais" do texto literário, e, mais do que isso, de "ir além dele, mas sem jamais perdê-lo de vista" (PAES, 1995, p.5-6). 0 autor cultivava imenso gosto pelo jogo de ideias e imagens intrínseco à literatura. 0 depoimento a seguir, acerca dos ensaios publicados no livro Transleituras (1995), revela a "capacidade associativa" do próprio escritor enquanto consumidor de narrativas:

Se alguma pretensão [as transleituras do livro] alimentam, só pode ser a de eventualmente estimular nos leitores o mesmo gosto do autor delas pelo jogo de idéias e pela associação da leitura de momento com o cabedal de leituras já feitas, por mais caprichosa ou disparatada que tal associação possa parecer. É graças a esse tipo de jogo associativo que 0 ato de leitura, sem abdicar em nenhum momento da sua condição de ato de prazer, alcança ser ao mesmo tempo um ato de progressivo enriquecimento espiritual (PAES, 1995, p. 6).

No presente artigo, o conceito (literário) de "transleitura" serve de base às pretensões do vocábulo a balizar a investigação aqui almejada: ao pretender a problematização dos processos de edição e transcriação do discurso científico em meios impressos, parte-se do princípio de que os consumidores de narrativas jornalísticas sobre a ciência revelam-se transleitores por natureza. Todos, afinal, "trazem à lembrança" não apenas outros textos e artigos já lidos e/ou estudados acerca 
de temas especializados, mas inúmeras experiências vivenciadas, ao longo dos anos, em relação à prática e ao discurso científico.

Daí nasce, justamente, 0 cerne da problematização que ora se pretende realizar: ao transformar o discurso do cientista em narrativa palatável a diversos tipos de leitores, que natureza de transcriação - e não apenas "tradução" - da ciência seria necessária à implementação de diálogos realmente profícuos entre público e narrativa jornalística?

\section{Sobre a "transcriação jornalística"}

Conforme já enfatizado neste artigo, Destácio (2000) enumera 16 pressupostos para 0 "bom jornalismo científico". Dentre os ideais sugeridos pelo autor, destaque para questões relativas ao "patrimônio da maioria"; ao valor humanitário dos conhecimentos adquiridos/ descobertos pela ciência; ao "caráter coletivo da prática científica"; à nobreza da concisão; à humanização das narrativas, à distinção entre especulações e resultados e à adequação entre forma e linguagem, com vistas às demandas do público.

Apesar da relevância dos princípios éticos incluídos na maior parte das sugestões do pesquisador, percebe-se como essencial, neste momento, a discussão em torno do ajustamento entre linguagem, forma e necessidades de público. Trata-se do principal ponto discutido nesta breve elucubração: qual seria, afinal, o melhor modo de "transcriar" o discurso da ciência, de maneira a ampliar compreensão de públicos-alvo tidos por "leigos"? Por fim, com base no referido questionamento, por que a tensão devidamente sublinhada - entre aspas - com relação aos termos "traduzir" e "transcriar"?

Complexas, as respostas iniciais às duas questões servirão de ponto de confluência de certos apontamentos desenvolvidos ao longo deste artigo. Primeiramente, no que diz respeito ao "melhor modo" de traduzir/recriar - jornalisticamente - o discurso da ciência, importante 0 retorno ao conceito de transleitura, de Paes, e a algumas das noções aqui indicadas a partir dos pensamentos de Campos e Ricoeur acerca do processo de tradução.

Importante começar, neste sentido, do "universo" daquele que consumirá o "material traduzido":

o que dizer da(s) experiência(s) do leitor/ espectador/usuário a quem é ofertada a narrativa jornalística sobre temáticas científicas?

Em primeiro lugar, enfatize-se a necessidade de aceitar o público da informação jornalística sobre ciência - bem como as fontes especializadas (os cientistas/pesquisadores) - como conjunto bastante "complexo", já que formado por indivíduos heterogêneos, instáveis e "munidos" de (trans) experiências diversas sobre o tempo, a vida $\mathrm{e}-0$ que aqui importa de modo específico as práticas científicas. 
Neste cenário, a ideia de transleitura proposta por José Paulo Paes no território das investigações literárias - revela-se também adaptável a certos desafios do jornalismo científico. Isso porque, ao pretender a decodificação do discurso da ciência, os jornalistas especializados precisarão ter a noção de que a própria ideia do que seja a especificidade da prática científica jamais se dissociará das múltiplas "experiências vividas" tanto pelos pesquisadores (fontes primárias) quanto pelos leitores/espectadores/usuários (público-fim dos produtos jornalísticos).

Diante de transleitores, pois, seria impossível imaginar uma espécie de tradução jornalística "absoluta e/ou perfeita" do discurso da ciência. Por isso, em analogia aos estudos de Campos (2015) e Ricoeur (2011), é imprescindível que se admita a inevitabilidade de certas impossibilidades/perdas - no caso, referentes à tradução do discurso científico e, mesmo, de formas de inteligibilidade da ciência. Ora, se sujeitos com (trans) experiências interpretarão informações jornalísticas de maneira absolutamente distinta - em função do "corredor de ecos" pessoais, culturais, intelectuais, políticos, religiosos, linguísticos, etc. ao qual tiveram acesso, individualmente -, o que restará aos profissionais do jornalismo?

De forma direta, defende-se, aqui, o pressuposto de que o próprio "desejo de traduzir" do jornalista científico possa lhe servir de sustentáculo à superação do complexo dilema "traduzível versus intraduzível" (RICOEUR, 2011) e/ou em busca de "isomorfia" (CAMPOS, 2015) - conceitos empregados, no caso, à transposição do rigoroso discurso da ciência ao universo linguístico/ cognitivo de leitores/espectadores/usuários com vasta potencialidade de transleitura. Que tal pensar na criação de narrativas jornalísticas repletas de equivalências presumidas e que aproximem 0 "discurso científico" - "0 estrangeiro em estrangeiridade" de Ricoeur - do transleitor, sujeito em "[permanente] desejo de apropriação")?

Infere-se que, ao criar novos modos de "dizer a ciência" - e não apenas de traduzi-la -, 0 jornalista vivencie a "hospitalidade linguística" nascida, justamente, do luto gerado em função da impossibilidade da tradução "absoluta/perfeita". Neste ponto, em nome do "horizonte razoável do desejo de traduzir" jornalisticamente 0 discurso científico, que tal pensar na substituição do vocábulo "tradução" pelo neologismo "transcriação"?

Com 0 objetivo de detalhar 0 referido termo, somese, aos princípios teóricos a ele concedidos por Campos (2015), a máxima de que o prefixo "trans" - conforme esclarece Paes (1995, p. 5), também em estudos literários - pretende "acentuar que a leitura de uma obra [...] é um ato de imersão e de distanciamento a um só tempo". Quanto ao vocábulo "criação", o importante a frisar está no fato de que a decodificação jornalística do discurso científico carecerá, ininterruptamente, 
de invenções e (re)reinvenções narrativas - ou "recriações", segundo Campos -, pois, superado 0 luto da impossibilidade da (mera) "tradução" sem perdas, haverá necessidade de criar - linguística e culturalmente - um novo discurso, capaz - em analogia a Ricoeur - de "levar a ciência ao leitor" e, ao mesmo tempo, de "levar o leitor à ciência".

\section{Considerações finais}

Do ponto de vista da ampliação do criticismo público quanto aos valores da ciência, o ofício da transcriação jornalística revela-se ético por natureza, pois, afora as ações básicas da prática cotidiana dos profissionais da área - delineamento de pauta, angulação, apuração e escrita -, será preciso (re)inventar modos de ampliação do diálogo entre discurso científico e sociedade. Trata-se, como já observado, de produtos/ações que ultrapassem os princípios cartesianos ainda em voga.

Neste cenário, defende-se a existência de projetos jornalísticos - passíveis de verificação empírica em trabalhos futuros - calcados no investimento em narrativas que, simultaneamente, informem e estimulem o debate em torno de questões caras ao universo da ciência, a exemplo de temas como a função da pesquisa - e dos pesquisadores - no mundo contemporâneo, 0 posicionamento sociopolítico dos indivíduos frente ao desenvolvimento tecnológico e a derrocada da razão cartesiana como princípio balizador das relações humanas.
Daí, aliás, o desafio central do processo de transcriação jornalística - anticartesiana e antipositivista - do discurso da ciência: inventar (ou reinventar, encenar, etc.) formas mais democráticas e interativas de "dizer a ciência" - ou, de outra maneira, de estimular os transleitores a interações dialógicas com 0 universo da produção do conhecimento. Para tal, deve-se partir do pressuposto de que 0 público, mesmo que leigo em relação a uma série de temáticas, permanece a engendrar experiências bastante particulares com 0 universo da prática científica.

\section{Referências}

BRONOWSKI, Jacob. Interpretações da natureza. In: Magia, ciência e civilização. Lisboa: Edições 70, 1986. p.9-28.

BUENO, Wilson da Costa. Jornalismo, lobby e poder. In: Revista Parcerias Estratégicas. Número 13, dezembro de 2001.

BURKETT, Warren. Jornalismo científico - Como escrever sobre ciência, medicina e alta tecnologia para os meios de comunicação. Trad. de Antônio Trânsito. Rio de Janeiro: Forense Universitária, 1990.

CAMPOS, Haroldo. Transcriação. Marcelo Tápia, Thelma Médici Nóbrega (Org.). São Paulo: Perspectiva, 2015.

. Da transcriação: poética e semiótica da operação tradutora. In: CAMPOS, Haroldo.

Transcriação. Marcelo Tápia, Thelma Médici Nóbrega (Org.). São Paulo: Perspectiva, 2015.

COLOMBO, Furio. A notícia científica. In: Conhecer o jornalismo hoje. Lisboa: Editorial Presença, 1998. p.96-111 
DESTÁCI0, Mauro Celso. Breve ensaio sobre as peculiaridades do texto de divulgação científica. In:

Revista eletrônica Espiral. Ano 1, № 4 - julhosetembro, 2000. Seção Papiro. Disponível em < http:// www.eca.usp.br/nucleos/njr/espiral/papiro4.htm > . Acesso em 17 mar. 2005.

FAGUNDES, Vanessa Oliveira. Diálogo possível. In: COSTA, Mônica (org.). Ciência e imprensa - Convergências possíveis. Natal (RN): Editora Fapern, 2010. p.43-51

GUIMARÃES, Eduardo. Produção e circulação do conhecimento. Campinas (SP): Pontes Editores, 2001. . 0 acontecimento para a grande mídia e a divulgação científica. In: GUIMARÃES, Eduardo. Produção e circulação do conhecimento. Campinas (SP): Pontes Editores, 2001.

LEITE, Marcelo. 0 atraso e a necessidade - Jornalismo científico no Brasil. In: COSTA, Mônica (org.). Ciência e imprensa - Convergências possíveis. Natal (RN): Editora Fapern, 2010.

LYNCH, John; MOSLEY, Michael. Uma história da ciência - Experiência, poder e paixão. Trad. de Ivan Weisz Kuck. Revisão técnica de José Cláudio Reis. Rio de Janeiro: Zahar, 2011.

MAIA, Isaura Amélia de Sousa Rosaldo. A divulgação da ciência é direito do cidadão. In: COSTA, Mônica (org.). Ciência e imprensa - Convergências possíveis. Natal (RN): Editora Fapern, 2010. p.23-24.

MOTTA, Leda Tenório da. Céu acima: para um tombeau de Haroldo de Campos. São Paulo:

Perspectiva, 2005.

MOZZINI, Camila. A ascensão da concepção cartesiana ao jornalismo. Cadernos de comunicação. Volume 16, número 2, julho-dezembro, 2012. Disponível em < http://periodicos.ufsm.br/ccomunicacao/article/ view/6375/4933 >. Acesso em 11 dez. 2014.

OLIVEIRA, Fabíola. Jornalismo científico. São Paulo: Contexto, 2002.
ORLANDI, Eni P. Divulgação - A descoberta entre a ciência e a não-ciência. In: GUIMARÃES, Eduardo.

Produção e circulação do conhecimento. Campinas (SP): Pontes Editores, 2001.

PAES, José Paulo. Transleituras. São Paulo: Ática, 1995.

PEREIRA JR., Luiz Costa. Guia para a edição

jornalística. $3^{\mathrm{a}}$ ed. Petrópolis (RJ): Vozes, 2011.

PETER-PETERS, Hans. A interação entre jornalistas e peritos científicos - cooperação e conflito entre duas culturas profissionais. In: Revista de Comunicação e Linguagens - jornalismo 2000. TRAQUINA, Nelson (Org.), Lisboa Relógio d’água Editora, 2000. p. 213-235 REIS, José. A ciência e o homem. In: Educação é investimento. São Paulo, Ibrasa, 1968.

RICOEUR, Paul. Sobre a tradução. Belo Horizonte: UFMG, 2011.

SANTAELLA, Lucia. Transcriar, transluzir, transluciferar: a teoria da tradução de Haroldo de Campos. In: MOTTA, Leda Tenório da. Céu acima: para um tombeau de Haroldo de Campos. São Paulo: Perspectiva, 2005.

SANTOS, Boaventura de Souza. Introdução a uma ciência pós-moderna. Rio de Janeiro: Graal, 1989.

SILVA, Josimey Costa. Fiat Lux. In: COSTA, Mônica (org.). Ciência e imprensa - Convergências possíveis. Natal (RN): Editora Fapern, 2010. p.25-29.

TÁPIA, Marcelo. Apresentação. In: CAMPOS, Haroldo. Transcriação. Marcelo Tápia, Thelma Médici Nóbrega (Org.). São Paulo: Perspectiva, 2015.

THOMPSON, John B. Ideologia e cultura moderna. Trad. de Pedro A. Guareshi et al. Petrópolis: Vozes, 1990. . A mídia e a modernidade - Uma teoria social da mídia. Trad. de Wagner de Oliveira Brandão. Petrópolis: Vozes, 1998.

. A nova visibilidade. Trad. de Andrea

Limberto. In: Revista Matrizes. Número 2, abril de 2008. 
VIZEU, Alfredo. A produção de sentidos no jornalismo: da teoria da enunciação a enunciação jornalística.

Revista FAMECOS: mídia, cultura e tecnologia, v. 1, $\mathrm{n}^{0}$ 22,2003 .

VOGT, C.; KNOBEL, M.; CASTELFRANCHI, Y.;

EVANGELISTA, R.; GARTNER, V. Construindo um

barômetro da ciência e tecnologia na mídia. In: VOGT,

C. (Org.). Cultura científica: desafios. São Paulo:

EDUSP, 2006. p. 84-130.

ZAMBONI, Lilian Márcia Simões. Cientistas,

jornalistas e a divulgação científica - Subjetividade

e heterogeneidade no discurso da divulgação científica.

São Paulo: Autores Associados, 2001. 
From desire to translate to the transcreation: notes on the journalistic decoding of scientific discourse, based on concepts of Haroldo de Campos, José Paulo Paes and Paul Ricoeur

\section{Abstract}

Journalistic mechanisms of decoding and editing the discourse of science necessitate the redefinition of the specialized investigations, linked to various areas of knowledge, and the sublimation of technical terminology - transforming it into dialogic narrative, with language and format similar to audience (reader, viewer, user etc.). Based on the "transreading" notion of José Paulo Paes (1995), in dialogue with the challenges of the translation process approached by Paul Ricoeur (2011), this paper proposes the use of the neologism "transcreation" - created by Haroldo de Campos - to discuss practical aspects of the science journalism coverage practices.

\section{Keywords}

Scientific journalism. Transreading. Transcreation. Haroldo de Campos. José Paulo Paes. Paul Ricoeur.
De lo deseo de traducir a la transcreación: notas sobre la decodificación periodística del discurso científico, basado en conceptos de Haroldo de Campos, José Paulo Paes y Paul Ricoeur

\section{Resumen}

Los mecanismos periodísticos de decodificación y edición del discurso de la ciencia implica la necesidad de una redefinición de las investigaciones especializadas, vinculadas a diversas áreas del conocimiento, y la sublimación de la terminología técnica - transformándola en narrativa dialógica con el lenguaje y el formato más cercano de la(s) experiencia(s) del público objetivo (lector, espectador, usuario etc.). A partir de la noción de "translectura", creada por José Paulo Paes (1995), en diálogo con los desafíos del proceso de traducción abordado por Paul Ricoeur (2011), este artículo propone el uso del neologismo "transcreación" - creado por Haroldo de Campos - para discutir las prácticas de cobertura periodística de la ciencia.

\section{Palabras clave}

Periodismo científico. Translectura. Transcreación.

Haroldo de Campos. José Paulo Paes. Paul Ricoeur. 


\section{Expediente}

A revista E-Compós é a publicação científica em formato eletrônico da Associação Nacional dos Programas de Pós-Graduação em Comunicação (Compós). Lançada em 2004, tem como principal finalidade difundir a produção acadêmica de pesquisadores da área de Comunicação, inseridos em instituições do Brasil e do exterior.

\section{E-COMPÓS I www.e-compos.org.br I E-ISSN 1808-2599}

Revista da Associação Nacional dos Programas de Pós-Graduação em Comunicação. Brasília, v.19, n.2, maio/ago. 2016. A identificação das edições, a partir de 2008, passa a ser volume anual com três números. Indexada por Latindex I www.latindex.unam.mx

\section{CONSELHO EDITORIAL}

\section{Alexandre Farbiarz, Universidade Federal Fluminense, Brasi}

Alexandre Rocha da Silva, Universidade Federal do Rio Grande do Sul, Brasil Ana Carolina Escosteguy, Pontifícia Universidade Católica do Rio Grande do Sul, Brasil Ana Carolina Rocha Pessôa Temer, Universidade Federal de Goiás, Brasil Ana Regina Barros Rego Leal, Universidade Federal do Piauí, Brasil Andrea França, Pontifícia Universidade Católica do Rio de Janeiro, Brasil André Luiz Martins Lemos, Universidade Federal da Bahia, Brasil Antonio Carlos Hohlfeldt, Pontifícia Universidade Católica do Rio Grande do Sul, Brasil Arthur Ituassu, Pontifícia Universidade Católica do Rio de Janeiro, Brasil Álvaro Larangeira, Universidade Tuiuti do Paraná, Brasil

Ângela Freire Prysthon, Universidade Federal de Pernambuco, Brasil César Geraldo Guimarães, Universidade Federal de Minas Gerais, Brasil Cláudio Novaes Pinto Coelho, Faculdade Cásper Líbero, Brasil Daisi Irmgard Vogel, Universidade Federal de Santa Catarina, Brasil Denize Correa Araujo, Universidade Tuiuti do Paraná, Brasil Eduardo Antonio de Jesus, Pontifícia Universidade Católica de Minas Gerais, Brasil Daniela Zanetti, Universidade Federal do Espírito Santo, Brasil Eduardo Vicente, Universidade de São Paulo, Brasil

Elizabeth Moraes Gonçalves, Universidade Metodista de São Paulo, Brasil Erick Felinto de Oliveira, Universidade do Estado do Rio de Janeiro, Brasil Francisco Elinaldo Teixeira, Universidade Estadual de Campinas, Brasil Francisco Paulo Jamil Almeida Marques, Universidade Federal do Paraná, Brasil Gabriela Reinaldo, Universidade Federal do Ceará, Brasil

Goiamérico Felício Carneiro Santos, Universidade Federal de Goiás, Brasil Gustavo Daudt Fischer, Universidade do Vale do Rio dos Sinos, Brasil Herom Vargas, Universidade Municipal de São Caetano do Sul, Brasil Itania Maria Mota Gomes, Universidade Federal da Bahia, Brasil Janice Caiafa, Universidade Federal do Rio de Janeiro, Brasil Jiani Adriana Bonin, Universidade do Vale do Rio dos Sinos, Brasil
José Afonso da Silva Junior, Universidade Federal de Pernambuco, Brasil José Luiz Aidar Prado, Pontifícia Universidade Católica de São Paulo, Brasil Juçara Gorski Brittes, Universidade Federal de Ouro Preto, Brasil Kati Caetano, Universidade Tuiuti do Paraná, Brasil Lilian Cristina Monteiro França, Universidade Federal de Sergipe, Brasil Liziane Soares Guazina, Universidade de Brasilia, Brasil Luíza Mônica Assis da Silva, Universidade de Caxias do Sul, Brasil Luciana Miranda Costa, Universidade Federal do Pará, Brasil Malena Segura Contrera, Universidade Paulista, Brasil Monica Martinez, Universidade de Sorocaba, Brasil Maria Ataide Malcher, Universidade Federal do Pará, Brasil Marcia Tondato, Escola Superior de Propaganda e Marketing, Brasil Marcel Vieira Barreto Silva, Universidade Federal da Paraiba, Brasil Maria Clotilde Perez Rodrigues, Universidade de São Paulo, Brasil Maria das Graças Pinto Coelho, Universidade Federal do Rio Grande do Norte, Brasil Mauricio Ribeiro da Silva, Universidade Paulista, Brasil

Mauro de Souza Ventura, Universidade Estadual Paulista, Brasil Márcio Souza Gonçalves, Universidade do Estado do Rio de Janeiro, Brasil Micael Maiolino Herschmann, Universidade Federal do Rio de Janeiro, Brasil Mirna Feitoza Pereira, Universidade Federal do Amazonas, Brasil Nísia Martins Rosario, Universidade Federal do Rio Grande do Sul, Brasil Potiguara Mendes Silveira Jr, Universidade Federal de Juiz de Fora, Brasil Regiane Regina Ribeiro, Universidade Federal do Paraná, Brasil Rogério Ferraraz, Universidade Anhembi Morumbi, Brasil Rose Melo Rocha, Escola Superior de Propaganda e Marketing, Brasil Rozinaldo Antonio Miani, Universidade Estadual de Londrina, Brasil Sérgio Luiz Gadini, Universidade Estadual de Ponta Grossa, Brasil Simone Maria Andrade Pereira de Sá, Universidade Federal Fluminense, Brasil Veneza Mayora Ronsini, Universidade Federal de Santa Maria, Brasil Walmir Albuquerque Barbosa, Universidade Federal do Amazonas, Brasil
COMISSÃO EDITORIAL Eduardo Antonio de Jesus, Pontifícia Universidade Católica de Minas Gerais, Brasil I Osmar Gonçalves dos Reis Filho, Universidade Federal do Ceará, Brasi

CONSULTORES AD HOC Alexandre Almeida Barbalho, Universidade Estadual do Ceará, Brasil | Alexandre Rocha da Silva, Universidade Federal do Rio Grande do Sul, Brasil | Bruno Souza Leal, Universidade Federal de Minas Gerais, Brasil I Carlos Eduardo Franciscato, Universidade Federal do Sergipe, Brasil I Eneus T. Barreto Filho, Universidade de São Paulo, Brasil I Felipe da Costa Trotta, Universidade Federal Fluminense, Brasi | Henrique Codato, Universidade Federal do Ceará, Brasil I Ines S. Vitorino Sampaio Universidade Federal do Ceará, Brasil I Jairo Getulio Ferreira, Universidade do Vale do Rio dos Sinos, Brasil I Juliana Freire Gutmann, Universidade Federal da Bahia, Brasil | Júlio César M. Pinto, Pontifícia Universidade Católica de Minas Gerais, Brasil I Lucrecia D. Ferrara, Pontifícia Universidade Católica de São Paulo, Brasil I Marcio V. Serelle, Pontifícia Universidade Católica de Minas Gerais, Brasil I Maria Ignes C. Magno, Universidade Anhemb Morumbi, Brasil I Maria Lilia Dias de Castro, Universidade Federal de Santa Maria, Brasil Mozahir S. Bruck, Pontifícia Universidade Católica de Minas Gerais, Brasil I Potiguara M. da Silveira Junior, Universidade Federal de Juiz de Fora, Brasil I Sandra Maria L. P. Gonçalves, Universidade Federal do Rio Grande do Sul, Brasil I Suzana Kilpp, Universidade do Vale do Rio dos Sinos, Brasil I Tiago Q. Fausto Neto, Universidade de Brasília, Brasil I Vera Regina V. Franca, Universidade Federal de Minas Gerais, Brasil I Virginia P. S. Fonseca, Universidade Federal do Rio Grande do Sul, Brasil

EQUIPE TÉCNICA ASSISTENTE EDITORIAL Márcio Zanetti Negrini REVISÃo DE TEXTOS Press Revisão I EDITORAÇÃO ELETRÔNICA Roka Estúdio

\section{COMPÓS I www.compos.org.br}

Associação Nacional dos Programas de Pós-Graduação em Comunicação

Presidente

Edson Fernando Dalmonte

Programa de Pós-Graduação em Comunicação

e Cultura Contemporânea - UFBA

edsondalmonte@uol.com.br

Vice-presidente

Cristiane Freitas Gutfreind

Programa de Pós-Graduação em Comunicação Social - PUC-RS cristianefreitas@pucrs.br

Secretário-Geral

Rogério Ferraraz

Programa de Pós-Graduação em Comunicação

Universidade Anhembi Morumbi

rogerioferraraz@anhembimorumbi.edu.br

CONTATO I revistaecompos@gmail.com 